\title{
Impact of Social Determinants of Health on Chronic Kidney Disease: A Review of Disparities in Renal Transplantation
}

\author{
Conner V. Lombardi (D) ${ }^{a}$ Logan D. Glosser ${ }^{a}$ Hanna M. Knauss ${ }^{a}$ Teanya Norwood ${ }^{b}$ Julia T. Berry ${ }^{a}$ Obinna O. Ekwenna
}

Corresponding author(s): Conner.Lombardi@ rockets.utoledo.edu

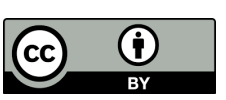
${ }^{a}$ University of Toledo College of Medicine and Life Sciences, Toledo, Ohio, 43560, USA, ${ }^{b}$ Promedica Toledo Hospital, Department of Care Navigation, Toledo, Ohio,
USA, and ${ }^{c}$ University of Toledo Medical Center, Department of Urology, Toledo, Ohio, 43560, USA

\begin{abstract}
Background: Striking disparity exists in the incidence and treatment of chronic kidney disease (CKD) secondary to individual social determinants of health. Additionally, the uninsured, minority racial-ethnic groups, and Medicaid enrollees receive less nephrology care prior to being diagnosed with end-stage renal disease (ESRD). The most effective treatment for the management of kidney failure is kidney transplantation. This review addresses how social determinants of health impact the workup for patients with ESRD, with emphasis on the kidney transplant process. Methods: A search was conducted via multiple online databases (MedLine, PubMed, etc.) for articles that addressed the interplay between CKD, ESRD and kidney transplantation with the social determinants of health. Findings: The impact of the social determinants of health on CKD, ESRD, and the kidney transplantation process can be qualitatively and quantitatively measured using the five categories of education, health care and access, economic stability, neighborhood and built environment, and social and community context. Conclusion: Social determinants of health impact outcomes in CKD, ESRD, and kidney transplantation. Public and private initiatives aimed at reducing social disparities among patients with kidney disease must include emphasis on education, health care and access, economic stability, neighborhood and built environment, and social and community context. This initiative is necessary to prevent progression to ESRD and to ensure quality care in the kidney transplantation process.
\end{abstract}

| End Stage Renal Disease | Kidney Failure | Dialysis | Socioeconomic Factors I Health care and access I

pproximately $13 \%$ of adults in the United States have CKD, many of whom are unaware of their condition.(1) The total Medicare spending on both CKD and ESRD patients exceeds \$120 billion annually.(2) The cost of Medicare patients with ESRD accounts for $7 \%$ of total Medicare Fee-For-Service spending (3). Health Care Financing Administration (HCFA) data demonstrate that dialysis costs $\$ 32,000$ per year, versus a one-time cost of $\$ 56,000$ for a kidney transplant with $\$ 6,400$ annually for posttransplant care (4-7). Therefore, treatment of ESRD with a kidney transplant reduces the financial cost exponentially after 3 years compared to dialysis. Additionally, the uninsured, minority racialethnic groups, and Medicaid enrollees receive less nephrology care before the diagnosis of ESRD (8).

Kidney transplant is the preferred therapy for patients with ESRD, as it not only reduces financial burden on the healthcare system, but also procures increased patient survival and quality of life. The five-year survival in patients with kidney transplant is $86 \%$, compared to $53 \%$ in hemodialysis.(9) As such, kidney transplant has become a target for health incentives. As part of the nationwide initiative to improve the health of all people, the Healthy People 2030 outlined the objective of "increasing the proportion of people who get a kidney transplant with 3 years of end-stage kidney disease treatment" (10).

To improve access to kidney transplants, there is a need to identify and address factors outside of genetic predisposition that influences ESRD treatment. Evidence suggests striking disparity in the

Submitted: 07/26/2021, published: 11/22/2021.

Freely available online through the UTJMS open access option 
incidence and treatment of CKD secondary to differences in individual patients' economic stability, education, social and community factors, and insurance coverage $(4-7,11)$.

The kidney transplant process is comprised of three phases: 1) pre-transplant evaluation 2) wait-listing 3) surgical/post-operative period. In the pre-transplant phase, health providers review relevant medical information, insurance, finances, and social support. This stage screens patients for exclusion criteria to determine waitlist eligibility. The pre-transplant phase includes a review of patient information and placement into one of three categories: eligible for a national donor waitlists, ineligible for the waitlist requiring further evaluation and treatment, or unlikely to be eligible for transplantation (6). This process is a continuum in which patients can be switched from one category to another at any time, depending on specific health maintenance, access to care and patient compliance.

Although eligibility criteria for kidney transplant vary slightly by institution, there are universal guidelines that patients must fulfill (12). Once deemed eligible for waitlist placement, patients wait for a donor kidney compatible with the recipient's immune system to become available. Patients must commit to rigorous health maintenance until a donor is identified. Such measures include regular appointments with treatment teams, compliance with medical management of existing comorbidities, adherence to a kidney failure dietary plan, and if necessary, continue dialysis treatment multiple times per week (12). Even transient illnesses such as the common cold can delay or deter the transplant procedure. Maintaining an active status on the waitlist requires a strict regimen affected by socio-economic barriers to eligibility. Patients with smaller social networks, lower income levels, and minimal or no insurance are more likely to be put on the inactive list and less likely to achieve eligibility for placement on the active waitlist $(6,7)$.

Average wait time for a kidney from the national deceased donor waitlist is 3.6 years, with significant variability dependent on an individual's health, compatibility, and the availability of donated organs (2). Several socioeconomic factors have been identified that impact the access to healthcare, and lower the chance of 5-year survival regardless of treatment modality.(13) Absolute contraindications to solid organ transplant and thus land patients on the inactive list include: malignancy, abuse of drugs, alcohol, or other substances, severe cardiac disease with ejection fraction $<25 \%$, BMI $>40$, severe pulmonary hypertension refractory to treatment, documented history of patient non-compliance with medical therapy, and inadequate social support (14).

If a donor match is found, the recipient must receive the transplant within 36 hours of deceased donor kidney availability.(15) Following transplant, patients must comply with immunosuppressive therapy, infectious prophylaxis, and strict dietary habits. Routine follow-up with the transplant team is mandated to monitor for rejection, postoperative complications, and other etiologies of kidney damage.

\section{Education}

Socioeconomic factors such as poverty, unemployment, and lower education level have adverse effects on health outcomes. Education not only serves as the foundation for occupation and income, but is also strongly linked with health-promoting behaviors of nutritious diet, physical activity, and avoidance of risky behaviors.(16) Additionally, lower education is associated with decreased sense of control over life events, lower self-confidence, and less motivation to seek care (17).

Schaeffner et al demonstrated that patients who receive a transplant consultation without completion of at least a high school education are three times less likely to be placed on a waitlist.(18) Furthermore, lower levels of educational achievement affect dialysis modality selection and transplant success. Patients with higher education have demonstrated better graft and patient recipient survival, irrespective of race (19).

The transplant process is a complex progression from determining suitability, following medical management, and social support. Lack of patient education on kidney disease reinforces disparities observed in the evaluation of transplant and subsequent prognosis $(17,20)$. The renal transplant process is difficult even for those with high educational attainment, and serves an even greater barrier for those less educated. Moreover, nephrology providers may be reluctant to refer less educated patients for transplant consultation. The referral bias prolongs dialysis care and reduces the chance of eventual treatment with a transplant (11).

\section{Health care and access}

Health comorbidities including diabetes, hypertension, heart disease, and family history of kidney failure are well known predisposing factors to CKD (21.) To decrease the incidence of CKD, it is imperative to optimize medical management for diabetes and hypertension (22). Socioeconomic status (SES) and insurance affect access to screening for CKD and prevention of progression to ESRD. $10 \%$ of adults with non-dialysis dependent CKD are uninsured and do not receive necessary treatment to deter progression to ESRD (23). Maintaining medical records for uninsured patients remains challenging, as there is no system to screen or implement preventative measures in patients not regularly seeking care. These patients are essentially "invisible" to the healthcare system (24).

Since the turn of the century and initiation of the Affordable Care Act, state Medicaid expansions to cover low-income adults improved access to care by extended screening and prevention of ESRD. Consequently, adjusted all-cause mortality rates reduced by 19.6 deaths per 100,000 adults (25). Despite efforts to expand insurance coverage for patients with CKD, hospitals and surgeons are evaluated by patient outcomes following kidney transplantation. Criteria to identify low-performing institutions was intended to reduce risk and allow equitable allocation of resources to increase transplant success (26). The flagging of low-performance centers has unintended consequences. Transplant facilities responded to systemic outcomes-based evaluation by selecting the lowest risk patients for kidney transplant, despite evidence that many more patients with ESRD would benefit from the procedure compared to continuing dialysis (27). Healthcare reimbursement based on value instead of volume has many benefits, but simultaneously removes uninsured and socioeconomically deprived patients from receiving kidney transplantation (28).

\section{Economic stability}

The association between socioeconomic status and health outcomes is well documented in patients with $\operatorname{CKD}(29,30)$. Volkova et al. found that persons living in neighborhoods $>20 \%$ below the federal poverty level had over three times higher incidence of ESRD compared to those living $<5 \%$ below the federal poverty level (31).

Socioeconomic factors influencing the onset of CKD and progression to ESRD are similar to those affecting outcomes following kidney transplant. Lower income and poor quality of insurance coverage (Medicaid or no insurance) are associated with lower graft 


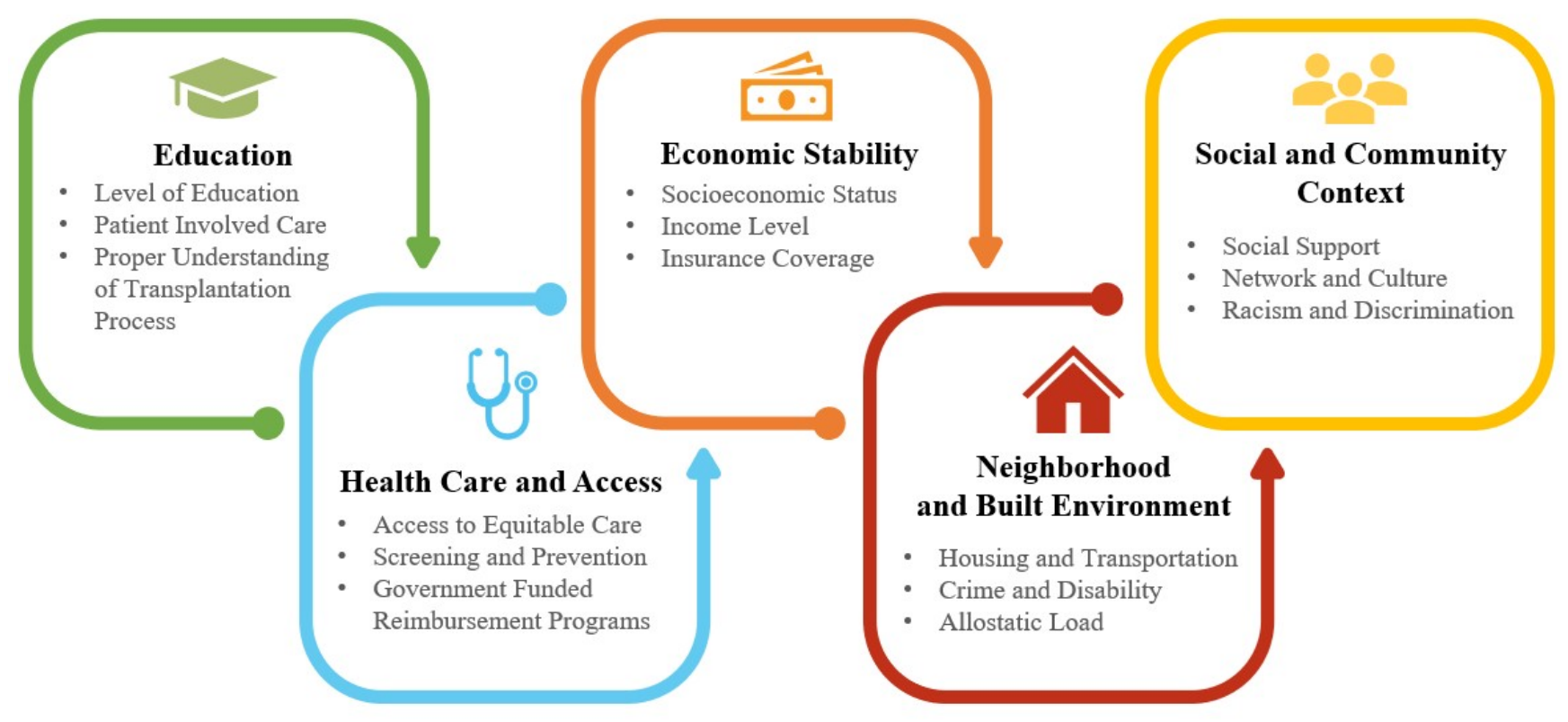

Figure 1. The Social Determinants of Health on CKD/ESRD and the kidney transplantation process can be divided into five categories: Education, Health Care and Access, Economic Stability, Neighborhood and Built Environment, Social and Community Context.

survival (32). The rate of graft failure and number of days with impaired functional status upon receiving a kidney transplant is higher in patients living in poverty.(33) Poverty does not independently predict kidney graft survival when controlling for other variables (33). Although disparities in the quality of life (QOL) after transplant have been reported to depend on race/ethnicity, a patients' socioeconomic status has a stronger association with differences in QOL (33).

There are several barriers facing patients referred for kidney transplant that confer loss to follow up or exclusion from referral. There are more for-profit dialysis facilities in poverty-ridden neighborhoods. Additionally, patients utilizing dialysis centers in such areas have lower referral rates for transplant evaluation (34). Disparities in transplant referral by race/ethnicity are not statistically significant when adjusting for socioeconomic factors and insurance coverage (35). Despite Medicare coverage for patients with ESRD, patients who only have Medicare insurance are associated with less preemptive placement on the transplant waitlist and longer duration of pre-transplant dialysis $(35,36)$.

Several studies have analyzed potential reasons for patients that are lost in follow-up during the renal transplant process, although more research is needed to determine the etiology. One qualitative study reported a patient had not sought kidney transplantation because they believed they "cannot afford transplant or medicines," suggesting an influence of perceived economic factors deterring patients from pursuing evaluation (37). Furthermore, patients with a higher income are more likely to receive a transplant, creating distrust in the process among lower income populations (38). This contributes to the disparity in access to kidney transplant fueled by differences in economic stability.

\section{Neighborhood and built environment}

The Healthy People 2030 initiative defines "neighborhood and built environment" as housing safety, access to nutritious food and recreation areas, transportation, access to healthcare, social order, neighborhood walkability, and unhealthy environmental exposures (39). There are many mechanisms by which residential neighborhood influences health outcomes. Specifically, residents of poor neighborhoods suffer from higher rates of ESRD with lower rates of kidney transplantation (31). The influence of disadvantaged neighborhoods on health is partially attributed to higher crime rates, disability, and depression, unequal access to quality education, and fewer recreational/employment opportunities (30). Chronic exposure to negative neighborhood factors on health outcomes occurs by allostatic load, defined as the cumulative physiological toll of experiencing and responding to stressors $(40,41)$.

The Department of Housing and Urban Development conducted a randomized experiment to determine the relationship between neighborhood environments and risk factors for CKD. The study found that moving out of poverty-ridden neighborhoods reduced such risk factors including morbid obesity and diabetes. The study found no significant differences in baseline characteristics and associated outcomes, suggesting that neighborhood characteristics exert an effect (42).

Both neighborhood poverty and racial diversity have an association with likelihood of placement on the transplant waitlist. In the United States, a higher percentage of disadvantaged neighborhoods are comprised of non-white Americans, contributing to racial disparity in $\mathrm{CKD}(43)$. Lastly, occupational and environmental exposures to toxins are linked to some forms of kidney disease.(44) Specifically, minority and disadvantaged populations are disproportionately exposed to toxins that affect kidney function such as lead, cigarettes, and alcohol (45).

\section{Social and community context}

Norton et al defines social support as "the network of people who exchange emotional, informational, and/or material assistance with individuals."(45) Greater social support is associated with im- 


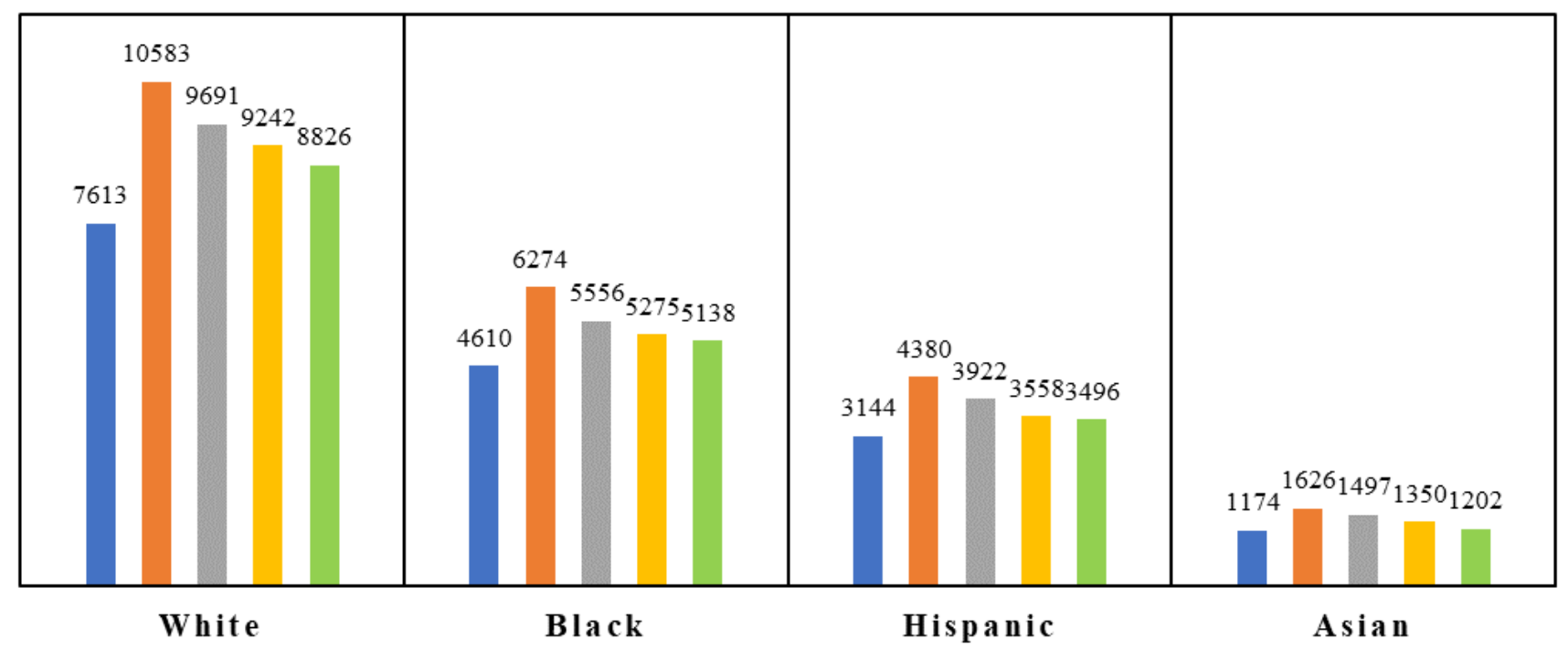

Figure 2. Fig II A summary of renal transplants conducted in the United States from 2016 until October 15, 2020 organized by race of kidney recipient (29).

proved outcomes in dialysis and kidney transplants, $(46,47)$ thus national guidelines require a social assessment for transplant eligibility. Social support has been strongly linked to kidney transplant listing decisions, although little evidence exists that it alters outcomes $(46,48,49)$.

Hall defines social and community context as: social norms, network and culture, community engagement, segregation and discrimination, and technology access. Within the community context, risk factors for poor kidney health include medical mistrust, perceived racism/discrimination, religious beliefs, and lack of social support $(31,50,51)$.

Disparities by race exist throughout the kidney transplantation process. African Americans are 3.5 times more likely to progress from early stage CKD to ESRD compared to white Americans and take 1.5 years longer to be accepted for a transplant (44). Nonwhite patients average longer periods of dialysis treatment prior to being waitlisted and less likely to receive a transplant (figure 2), which may be due to lower SES and less preemptive wait-listing (48). Earlier discussion initiated by providers about kidney transplant is associated with preemptive wait-listing, and thus could be used to reduce barriers in minority patients.(49) These racial disparities are eliminated when controlling for cultural and psychosocial characteristics (50).

Another possible explanation for racial differences in referral for kidney transplantation is provider bias and differences in care. Some evidence suggests that physicians alter the presentation of risks/benefits of transplantation to minority patients.(51) There is evidence that providers reinforce societal stereotypes and communicate lower expectations to certain groups, perpetuating health disparities. Additionally, patient-provider communication influence patients' health literacy, behavior, and access to care. Non-white patients are less likely to receive all relevant information about the option for kidney transplantation, which is linked to providerdirected differences in treatment recommendations and decision- making (52).

According to the CDC, in 2021, about $12.7 \%$ of white Americans, $16.3 \%$ of black Americans, $13.6 \%$ of Hispanic Americans, and $12.9 \%$ of Asian Americans are diagnosed with CKD (53). Thus, if the trend for kidney transplantation equally represented the racial breakdown of patients with CKD, there would be a higher volume of kidney transplants for patients of black, Hispanic, and Asian race than for patients of white race. However, illustrated in Fig 2, there is a disproportionate tendency for white patients to receive kidney transplants over patients of Black, Hispanic, and Asian race.

\section{Conclusion}

This review highlights the scope of disparities in outcomes in patients with ESRD and kidney transplantation in the United States. When assessing patients with ESRD, clinicians must take a multidisciplinary approach with awareness of socioeconomic factors to promote optimal treatment. Initiatives to reduce social disparities among patients with CKD must recognize patients' level of education, health care and access, economic stability, neighborhood and built environment, and social contexts. More research is needed to guide specific actions that can increase prevention of ESRD and ensure equal access to transplantation options.

\section{Conflict of interest}

Authors declare no conflict of interest.

\section{Authors' contributions}

LG and CL are joint senior authors, performed the literature review and wrote the majority of the paper. TN provided a quality review as a public health expert, JB and HK efforts included contextual review plus additions of the tables and figures, OE offered the conceptualization for and guided the directionality for submission 


\section{Acknowledgments}

We dedicate this research toward reducing disparities in CKP treatment and toward equitable and just care for all. We extended

1. Myers OB, Pankratz VS, Norris KC, Vassalotti JA, Unruh ML, Argyropoulos C. (2018) Surveillance of CKD epidemiology in the US - a joint analysis of NHANES and KEEP. Sci Rep. 8(1):15900.

2. Johansen KL, Chertow GM, Foley RN, Gilbertson DT, Herzog CA, Ishani A, et al. (2021) US Renal Data System 2020 Annual Data Report: Epidemiology of Kidney Disease in the United States. Am J Kidney Dis. 77(4 Suppl 1):A7-A8.

3. Ahmed O, Patel K, Rabei R, Patel MV, Ginsburg M, Clayton B, et al. (2018) Hemodialysis Access Maintenance in the Medicare Population: An Analysis Over a Decade of Trends by Provider Specialty and Site of Service. J Vasc Interv Radiol. 29(2):159-69.

4. Richard A RN. (1991)Institute of Medicine (US) Committee for the Study of Medicare End-Stage Renal Disease Program. Washington (DC): National Academies Pressu (US).

5. Axelrod DA, Dzebisashvili N, Schnitzler MA, Salvalaggio PR, Segev DL, Gentry SE, et al. (2010) The interplay of socioeconomic status, distance to center, and interdonor service area travel on kidney transplant access and outcomes. Clin $J$ Am Soc Nephrol. 5(12):2276-88.

6. Patzer RE, Perryman JP, Schrager JD, Pastan S, Amaral S, Gazmararian JA, et al. (2012) The role of race and poverty on steps to kidney transplantation in the Southeastern United States. Am J Transplant. 12(2):358-68.

7. Ladin K, Hanto DW. (2010) Understanding disparities in transplantation: do social networks provide the missing clue? Am J Transplant. 10(3):472-6.

8. Saran R, Robinson B, Abbott KC, Agodoa LY, Albertus P, Ayanian J, et al. (2017) US Renal Data System 2016 Annual Data Report: Epidemiology of Kidney Disease in the United States. Am J Kidney Dis. 69(3 Suppl 1):A7-A8.

9. Emma Aitken RS, Faisal Hanif, Diana Raj, Karen Stevenson, David Kingsmore. (2016) Renal Transplantation: An update for Anaesthetists. International Journal of Anesthetics and Anesthesiology. 3(4).

10. Chronic Kidney Disease Health.gov2020 [cited 2021 May 31]. Available from: https:/health.gov/healthpeople/objective-and-data/browse-objectives/chronickidney-disease.

11. Kucirka LM, Grams ME, Balhara KS, Jaar BG, Segev DL. (2012) Disparities in provision of transplant information affect access to kidney transplantation. Am J Transplant. 12(2):351-7.

12. Batabyal P, Chapman JR, Wong G, Craig JC, Tong A. (2012) Clinical practice guidelines on wait-listing for kidney transplantation: consistent and equitable? Transplantation. 94(7):703-13.

13. Kulkarni S, Ladin K, Haakinson D, Greene E, Li L, Deng Y. (2019) Association of Racial Disparities With Access to Kidney Transplant After the Implementation of the New Kidney Allocation System. JAMA Surg. 154(7):618-25.

14. Kiberd BA, AlBugami MM, Panek R, Tennankore K. (2015) Contraindications to kidney transplantation: uneven grounds? Transplant Res. 4:2.

15. Bond M, Pitt M, Akoh J, Moxham T, Hoyle M, Anderson R. (2009) The effectiveness and cost-effectiveness of methods of storing donated kidneys from deceased donors: a systematic review and economic model. Health Technol Assess. 13(38):iii-iv, xi-xiv, 1-156.

16. Mirowsky J, Ross CE. (2015) Education, Health, and the Default American Lifestyle. J Health Soc Behav. 56(3):297-306.

17. Patzer RE, Perryman JP, Pastan S, Amaral S, Gazmararian JA, Klein M, et al (2012) Impact of a patient education program on disparities in kidney transplant evaluation. Clin J Am Soc Nephrol. 7(4):648-55.

18. Schaeffner ES, Mehta J, Winkelmayer WC. (2008) Educational level as a determinant of access to and outcomes after kidney transplantation in the United States. Am J Kidney Dis. 51(5):811-8.

19. Goldfarb-Rumyantzev AS, Koford JK, Baird BC, Chelamcharla M, Habib AN, Wang BJ, et al. (2006) Role of socioeconomic status in kidney transplant outcome. Clin $J$ Am Soc Nephrol. 1(2):313-22.

20. Russell CL. (2006) Culturally responsive interventions to enhance immunosuppressive medication adherence in older African American kidney transplant recipients. Prog Transplant. 16(3):187-95; quiz 96.

21. Fraser SD, Blakeman T. (2016) Chronic kidney disease: identification and management in primary care. Pragmat Obs Res. 7:21-32.

22. Bello AK, Nwankwo E, EI Nahas AM. (2005) Prevention of chronic kidney disease: a global challenge. Kidney Int Suppl. (98):S11-7.

23. Olomu AB, Gourineni V, Huang JL, Pandya N, Efeovbokhan N, Samaraweera J, et al. (2013) Rate and predictors of blood pressure control in a federal qualified health center in Michigan: a huge concern? J Clin Hypertens (Greenwich). 15(4):254-63.

24. Hall YN, Rodriguez RA, Boyko EJ, Chertow GM, O'Hare AM. (2009) Characteristics of uninsured Americans with chronic kidney disease. $J$ Gen Intern Med. 24(8):917-22.

25. Sommers BD, Baicker K, Epstein AM. (2012) Mortality and access to care among adults after state Medicaid expansions. N Engl J Med. 367(11):1025-34. our gratitude to the University of Toledo School of Medicine, The Department of Urology.

26. Schold JD, Miller CM, Henry ML, Buccini LD, Flechner SM, Goldfarb DA, et al. (2017) Evaluation of Flagging Criteria of United States Kidney Transplant Center Performance: How to Best Define Outliers? Transplantation. 101(6):1373-80.

27. Schold JD, Buccini LD, Goldfarb DA, Flechner SM, Poggio ED, Sehgal AR. (2014) Association between kidney transplant center performance and the survival benefit of transplantation versus dialysis. Clin J Am Soc Nephrol. 9(10):1773-80.

28. Hippen BE, Maddux FW.(2018) Integrating kidney transplantation into valuebased care for people with renal failure. Am J Transplant. 18(1):43-52.

29. Transplants in the U.S. by Recipient Ethnicity 2020 [cited 2020 October 15]. Available from: https://optn.transplant.hrsa.gov/data/view-datareports/national-data/.

30. Phelan JC, Link BG, Tehranifar P. (2010) Social conditions as fundamental causes of health inequalities: theory, evidence, and policy implications. $J$ Health Soc Behav. 1 Suppl:S28-40.

31. Hall YN. (2018) Social Determinants of Health: Addressing Unmet Needs in Nephrology. Am J Kidney Dis. 72(4):582-91.

32. Volkova N, McClellan W, Klein M, Flanders D, Kleinbaum D, Soucie JM, et al. (2008) Neighborhood poverty and racial differences in ESRD incidence. $J$ Am Soc Nephrol. 19(2):356-64.

33. Gordon EJ, Ladner DP, Caicedo JC, Franklin J. (2010) Disparities in kidney transplant outcomes: a review. Nephrol. 30(1):81-9.

34. Press R, Carrasquillo O, Nickolas T, Radhakrishnan J, Shea S, Barr RG. (2005) Race/ethnicity, poverty status, and renal transplant outcomes. Transplantation. 80(7):917-24.

35. Patzer RE, Plantinga LC, Paul S, Gander J, Krisher J, Sauls L, et al. (2015) Variation in Dialysis Facility Referral for Kidney Transplantation Among Patients With End-Stage Renal Disease in Georgia. JAMA. 314(6):582-94.

36. Schold JD, Gregg JA, Harman JS, Hall AG, Patton PR, Meier-Kriesche HU. (2011) Barriers to evaluation and wait listing for kidney transplantation. Clin J Am Soc Nephrol. 6(7):1760-7.

37. Keith D, Ashby VB, Port FK, Leichtman AB. (2008) Insurance type and minority status associated with large disparities in prelisting dialysis among candidates for kidney transplantation. Clin J Am Soc Nephrol. 3(2):463-70.

38. Kazley AS, Simpson KN, Chavin KD, Baliga P. (2012) Barriers facing patients referred for kidney transplant cause loss to follow-up. Kidney Int. 82(9):1018-23.

39. Browne T, Amamoo A, Patzer RE, Krisher J, Well H, Gander J, et al. (2016) Everybody needs a cheerleader to get a kidney transplant: a qualitative study of the patient barriers and facilitators to kidney transplantation in the Southeastern United States. BMC Nephrol. 17(1):108.

40. Fielding JE, Teutsch S, Koh H. (2012) Health reform and Healthy People initiative. Am J Public Health. 102(1):30-3.

41. Stewart JA. (2006) The detrimental effects of allostasis: allostatic load as a measure of cumulative stress. J Physiol Anthropol. 25(1):133-45.

42. Ludwig J, Sanbonmatsu L, Gennetian L, Adam E, Duncan GJ, Katz LF, et al. (2011) Neighborhoods, obesity, and diabetes-a randomized social experiment. N Engl J Med. 365(16):1509-19.

43. Saunders MR, Cagney KA, Ross LF, Alexander GC. (2010) Neighborhood poverty, racial composition and renal transplant waitlist. Am J Transplant. 10(8):1912-7.

44. Said S, Hernandez GT. (2015) Environmental exposures, socioeconomics, disparities, and the kidneys. Adv Chronic Kidney Dis. 22(1):39-45.

45. Norton JM, Moxey-Mims MM, Eggers PW, Narva AS, Star RA, Kimmel PL, et al. (2016) Social Determinants of Racial Disparities in CKD. J Am Soc Nephrol. 27(9):2576-95.

46. Ladin K, Emerson J, Butt Z, Gordon EJ, Hanto DW, Perloff J, et al. (2018) How important is social support in determining patients' suitability for transplantation? Results from a National Survey of Transplant Clinicians. $J$ Med Ethics. 44(10):666-74.

47. Plantinga LC, Pastan SO, Wilk AS, Krisher J, Mulloy L, Gibney EM, et al. (2017) Referral for Kidney Transplantation and Indicators of Quality of Dialysis Care: A Cross-sectional Study. Am J Kidney Dis. 69(2):257-65.

48. Joshi S, Gaynor JJ, Bayers S, Guerra G, Eldefrawy A, Chediak Z, et al. (2013) Disparities among Blacks, Hispanics, and Whites in time from starting dialysis to kidney transplant waitlisting. Transplantation. 95(2):309-18.

49. Kutner NG, Zhang R, Huang $Y$, Johansen KL. (2012) Impact of race on predialysis discussions and kidney transplant preemptive wait-listing. Am J Nephrol. 35(4):305-11.

50. Myaskovsky L, Almario Doebler D, Posluszny DM, Dew MA, Unruh M, Fried LF, et al. 92012) Perceived discrimination predicts longer time to be accepted for kidney transplant. Transplantation. 93(4):423-9.

51. Ayanian JZ, Cleary PD, Keogh JH, Noonan SJ, David-Kasdan JA, Epstein AM. (2004) Physicians' beliefs about racial differences in referral for renal transplantation. Am J Kidney Dis. 43(2):350-7.

52. van Ryn M, Fu SS. (2003) Paved with good intentions: do public health and human service providers contribute to racial/ethnic disparities in health? Am J Public Health, 93(2):248-55 